\title{
Microencapsulation of Rosemary Essential Oil by Co-Extrusion/Gelling Using Alginate as a Wall Material
}

\author{
Celia Dolçà', Marcela Ferrándiz ${ }^{1}$, Lucia Capablanca² ${ }^{2}$, Esther Franco', Elena Mira1, \\ Fernanda López ${ }^{2}$, David García ${ }^{2}$ \\ ${ }^{1}$ Biotechnology Research Group, Textile Research Institute (AITEX), Alcoy, Spain \\ ${ }^{2}$ Polytechnic University of Valencia (UPV), Campus de Alcoy, Alcoy, Spain \\ Email: mferrandiz@aitex.es, lucafra@upvnet.upv.es
}

Received 1 July 2015; accepted 22 August 2015; published 25 August 2015

Copyright (C) 2015 by authors and Scientific Research Publishing Inc.

This work is licensed under the Creative Commons Attribution International License (CC BY).

http://creativecommons.org/licenses/by/4.0/

c) (i) Open Access

\begin{abstract}
An essential oil is the volatile lipophilic component extracted from plants. Microencapsulation systems protect the essential oil from degradation and evaporation, and at the same time allow a sustained release. This work analyzed and characterized the rosemary essential oil microcapsules prepared by co-extrusion technique using alginate as wall material and calcium chloride as cross linker. Several instrumental techniques were used: optical microscopy, coulter counter, Fourier transform infrared spectroscopy (FTIR), differential scanning calorimetry (DSC), termogravimetric analysis (TGA), spectrophotometry, antimicrobial test and chromatography. Results show that rosemary oil has pesticidal properties, and its microencapsulation allows knowing that these properties remain inside the microcapsules.
\end{abstract}

\section{Keywords}

Sodium Alginate, Rosemary Oil, Co-Extrusion, Gelling, FTIR, DSC, TGA

\section{Introduction}

Microencapsulation can, potentially, offer numerous benefits to active molecules being encapsulated. Various properties of active materials may be changed by this technique. For instance, handling and flow properties can be improved by converting a liquid to a powdered encapsulated form [1]. The main compounds of the essential oils responsible for the flavor and the functional properties are volatiles and chemical unstable in the presence of oxygen, moisture and heat [2]. Stability of essential oils can be enhanced through microencapsulation by differ-

How to cite this paper: Dolçà, C., Ferrándiz, M., Capablanca, L., Franco, E., Mira, E., López, F. and García, D. (2015) Microencapsulation of Rosemary Essential Oil by Co-Extrusion/Gelling Using Alginate as a Wall Material. Journal of Encapsulation and Adsorption Sciences, 5, 121-130. http://dx.doi.org/10.4236/jeas.2015.53010 
ent techniques, like co-extrusion/gelling.

Co-extrusion/gelling is an encapsulation process. This process happens when a fluid flows in laminar state and breaks into droplets of a same size through an overlap vibration. Then these drops transform into a gel in an ionic solution, resulting in encapsulation of the active ingredient (Core) with a polymer (Shell) [3].

Many essential oils such as garlic, cinnamon, thyme, oregano, clove, basil, coriander, citrus peel, eucalyptus, ginger, rosemary, and peppermint, among others, have been demonstrated antimicrobial activity [4]. Therefore these natural products are an alternative to replace synthetic chemical pesticides [5].

The interest in natural products having an antimicrobial activity to preserve food quantity and quality and in agriculture applications has increased, because they tend to have low mammalian toxicity, less environmental effects and wide public acceptance [2] [6]-[8].

Rosmarinus officinalis L. is widely accepted as one of the spices with the strongest aroma and the highest antioxidant activity. Rosemary has also been extensively studied due to its antimicrobial activity [9]. It has been reported that antibacterial, antioxidant and free radical-scavenging activities were exhibited by rosemary essential oil extracts, using steam distillation.

Rosemary essential oil has been encapsulated using spray dry techniques with different material shell in the food applications [10].

Biopolymers, like proteins and hydrocolloids, are used as encapsulating materials in different applications. Alginic acid sodium salt from brown algae, sodium alginate, is one example.

Algine has been used in microencapsulation process as a wall material. Alginic acid is a linear polymer based on two monomer units, $\beta$-D-mannuronic acid and $\alpha$-L-guluronic acid. The alginate polymer is formed by the joint of these monomers at the positions C-1 and C-4. An ether-oxygen bridge joins the carbon at the position 1 , in one molecule to the position 4 of another molecule. It has been shown that the polymer chain is made up of three kinds of regions or blocks. The G blocks contain only units derived from L-guluronic acid; the M blocks are based entirely on D-mannuronic acid and the MG blocks consist of alternating units from D-mannuronic acid and L-guluronic acid [10]-[15].

Gelation occurs when divalent ions $\left(\mathrm{Ca}^{2+}, \mathrm{Ba}^{2+}, \mathrm{Fe}^{2+}, \mathrm{Sr}^{2+}\right.$, etc.) or trivalent ions $\left(\mathrm{Al}^{3+}\right.$, etc.) take part in the interchain ionic binding between G-blocks in the polymer chain giving rise to a three dimensional network. Such binding zones between the G-blocks are often referred to as "egg boxes". These ions act as cross-linkers that stabilize alginate chains forming a gel structure, which contains cross-linked chains interspersed with more freely movable chains that bind and entrap large quantities of water. The gelification process is characterized by a re-organisation of the gel network accompanied by the expulsion of water [16].

This method presents several benefits like other encapsulation methods:

- One is that no heat is used in the process. The heat could cause deterioration of active materials (core) and shell materials.

- This technique allows controlling the amount of active material (core) encapsulated, and the membrane thick.

- The microencapsulation process is short, continuous, low cost industrial scale and protects the core material.

- Size and particle morphology are controllable.

- The size obtained in co-extrusion and gelling microencapsulation process is bigger than other kinds of microencapsulation processes, like spray drying. These microcapsules can be applied in different fields like agriculture, cosmetic and textile.

The aim of the present research is the microencapsulation of rosemary essential oil by co-extrusion/gelling using calcium alginate as a cross linker, in order to achieve their protection. Different instrumental techniques have been used in order to characterize the microcapsules obtained and demonstrate the pesticidal and antimicrobial properties.

\section{Materials and Methods}

\subsection{Materials}

A low viscosity alginic acid sodium salt from brown algae (Sigma Aldrich, Spain) was used as shell material. The core material was an essential oil, specifically, Rosemary oil (Ensencias Lozano, Spain). In order to observe the oil presence as a core material it was used a natural dye, Verde Cornasol C (Prochimac, Switzerland).

Calcium chloride (Sigma Aldrich, Spain) was used as cross-linking material [16]. 


\subsection{Experiment Design}

Experimental parameters were optimized in a previous research [17] [18]. They are showed in Table 1.

\subsection{Emulsion Preparation}

The alginate solution was prepared with $4 \%(\mathrm{w} / \mathrm{w})$. The alginic acid sodium salt was mixed with distilled water and kept in the fridge during $24 \mathrm{~h}$, in order to obtain the right viscosity and stabilize the emulsion.

Cross-linking agent, calcium chloride, was prepared at $0.5 \mathrm{M}$.

$1 \%$ of dye solution in the rosemary oil was used in order to observe and control the encapsulated oil, by spectrophotometry.

\subsection{Microencapsulation by Co-Extrusion}

Microcapsules were obtained by BUCHI B-390at room temperature. The internal nozzle diameter (core) was 0.2 $\mathrm{mm}$ and the external nozzle diameter (shell) was $0.4 \mathrm{~mm}$. Potential and frequency values were $250 \mathrm{~V}$ and 350 Hz. Oil flow and alginate flow were controlled by injection pump $(900 \mathrm{~mL} / \mathrm{h}$ and $300 \mathrm{~mL} / \mathrm{h}$ respectively), this difference is due to the solution viscosity.

Microcapsules were filtered and washed three times with distilled water in order to eliminate all the calcium chloride solution in the microcapsules wall (Figure 1 and Figure 2).

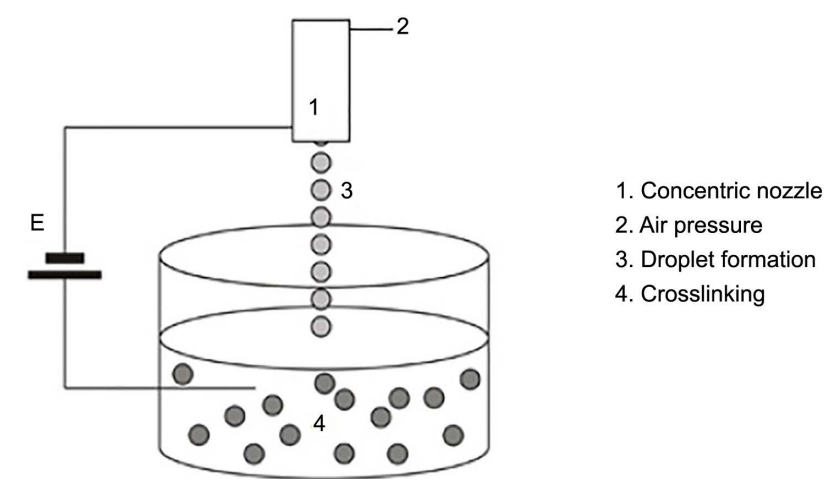

Figure 1. Microcapsules formation.
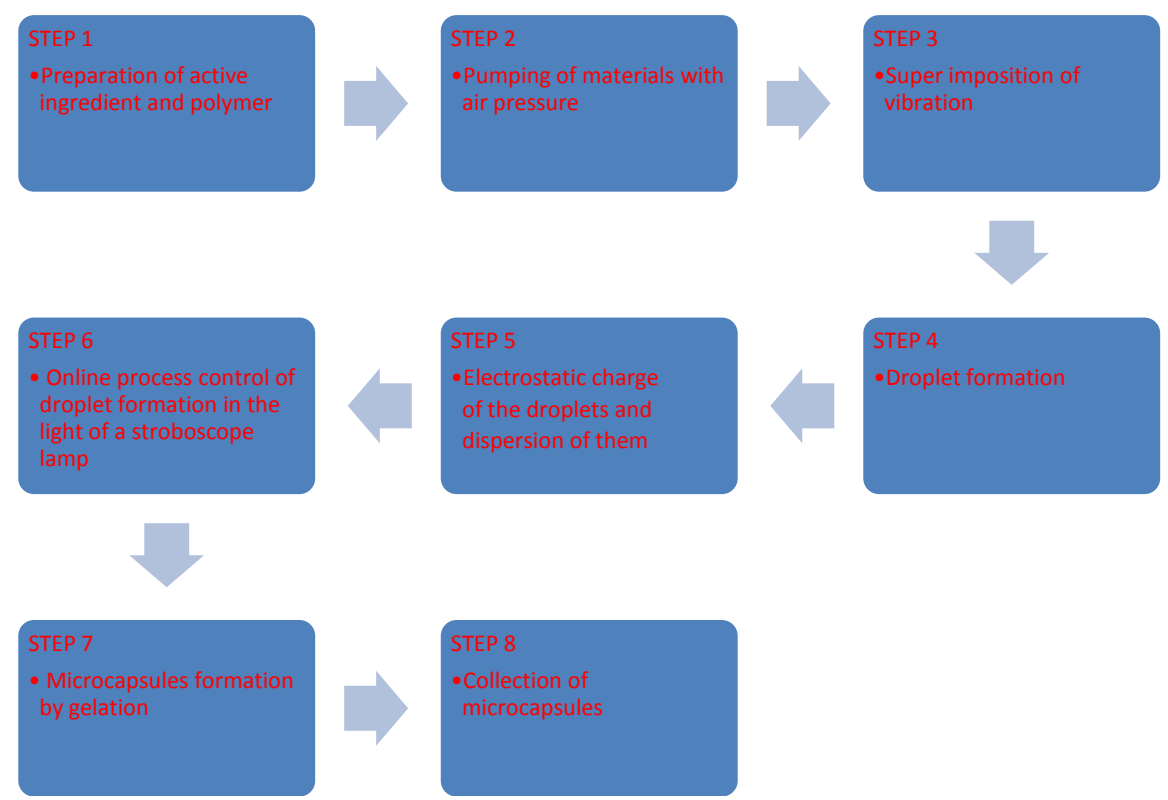

Figure 2. Process scheme. 
Table 1. Optimal parameters in co-extrusion/gelling process.

\begin{tabular}{cccc}
\hline & Optimal parameters & \\
\hline Alginate concentration $(\% \mathrm{w} / \mathrm{v})$ & $\mathrm{CaCl}_{2}$ concentration $(\mathrm{M})$ & Potential $(\mathrm{V})$ & Frequency $(\mathrm{Hz})$ \\
\hline 4 & 0.5 & 250 & 350 \\
\hline
\end{tabular}

\subsection{Drying}

Microcapsules were dried at $60^{\circ} \mathrm{C}$ during 2 hours. This temperature was selected due to the alginate gels formed at temperatures between $0^{\circ} \mathrm{C}$ to $100^{\circ} \mathrm{C}$, and because they do not melt when heated [19].

\section{Microcapsules Characterization}

\subsection{Morphology}

Microcapsules morphology was studied in an optic microscope AM4115ZT Dino-Lite Edge (Dino-Lite Digital Microscope, Taiwan) with a Dino-Capture Software.

The experiments were done with dry and non-dry microcapsules. They were repeated four times to compare the results between different microcapsules.

\subsection{Particle Size Distribution}

The microcapsules particle size distribution was measured by a Coulter ${ }^{\circledR}$ Counter apparatus (Multisizer 3, Coulter Electronics, Northwell, UK). The particle size was expressed as the equivalent volume diameter and three replicates were performed for each batch of microcapsule. To reduce error, an average curve was calculated and analyzed.

Samples were diluted 1:20 in an Isoton II Solution (Akralab, Spain) up to $10 \mathrm{~mL}$. Measures were performed at room temperature.

\subsection{Differential Scanning Calorimetry}

Differential scanning calorimetry Mettler-Toledo 821 (Mettler-Toledo Inc., Switzerland) was used to determinate the glass transition temperatures (Tg) of the dried microcapsules. Approximately $10 \mathrm{mg}$ of sample (dry microcapsules) was prepared in aluminum pans in air atmosphere. The curves were obtained according to the following heating program: to $0^{\circ} \mathrm{C}$ and $220^{\circ} \mathrm{C}$ at $5^{\circ} \mathrm{C} / \mathrm{min}$.

\subsection{Termogravimetry}

Termogravimetry (TGA/SDTA 851, Mettler-Toledo Inc., Switzerland) was used to determine the stability of the microcapsules in high temperatures. Approximately $70 \mu \mathrm{l}$ of sample (dry microcapsules) was prepared in aluminum pans. The thermal program was located between 0 and $220^{\circ} \mathrm{C}$ at $10^{\circ} \mathrm{C} / \mathrm{min}$ under nitrogen gas with a flow rate of $60 \mathrm{ml} \cdot \mathrm{min}^{-1}$.

\subsection{Spectrophotometry}

Control release was made with a spectrophotometric technic UV (Evolution 60S, Thermo Scientific, USA). It was necessary to use a dye in this technique due to the fact that rosemary oil is colorless.

The experiments were made with 0.5 gr of non-dry and dry microcapsules. They were repeated three times. To release the oil, it was put the same quantity of microcapsules and ethanol, and then sonicated for 10 minutes.

Previously, a calibration curve at $640 \mathrm{~nm}$ was made and the oil content was calculated by Lambert-beer method.

\subsection{Antimicrobial Test}

Rosemary essential oil and the microcapsules were tested to determinate antifungal/antibacterial activity, based on Standard ASTM E 2149-13. The contact time of the material with fungi was $24 \mathrm{~h}$ and the culture medium 
used was Sabouraud Dextrosa Agar (Sharlab, Spain). The contact time of the material with bacteria was $24 \mathrm{~h}$ and the Culture medium used was plate Count Agar (Sharlab, Spain). The Incubation temperature was $35^{\circ} \mathrm{C} \pm 2^{\circ} \mathrm{C}$.

Experiments were performed with dry microcapsules.

\subsection{Chromatography}

A Trace 1300 GC gas chromatograph equipped with a programmed split/splitless injector, an AI 1310 automatic sampler, and coupled to a single quadrupole mass detector (ISQ LT) was used to perform the GC-MS analysis (all from Thermo Scientific, San José, CA, USA). A Zebron ZB-5MS (30 m × $0.25 \mathrm{~mm}$ i.d., $0.25 \mu \mathrm{m}$ thickness) column was used (Phenomenex Torrance, CA, USA). Helium was used as carrier gas, at a flow rate of 1 $\mathrm{mL} / \mathrm{min}$.

The injector temperature was $250^{\circ} \mathrm{C}$. Samples were injected in the split mode (1:30). The injection volume was $1 \mu \mathrm{l}$. The oven temperature was programmed as follows: $40^{\circ} \mathrm{C}$ for $2 \mathrm{~min}$, then $310^{\circ} \mathrm{C}$ at $7^{\circ} \mathrm{C} / \mathrm{min}$, maintained for $5 \mathrm{~min}$.

\section{Results and Discussion}

\subsection{Morphology}

The results obtained show that non-dry microcapsules were not completely spherical. The core material has a spherical shape and the oil with dye is inside the wall, Figure 3.

The results of the morphology study are shown in Table 2.

Due to the core morphology, dry microcapsules presented more spherical shape than non-dry microcapsules.

Non-dry microcapsules area was bigger than the of the dry microcapsules. This is due to water loss in the drying process.

Certain differences can be observed between size microcapsules obtained (Table 2) and the external nozzle diameter $(0.4 \mathrm{~mm})$. This is due to equipment parameters like vibration frequency, flow rate, electrode tension,

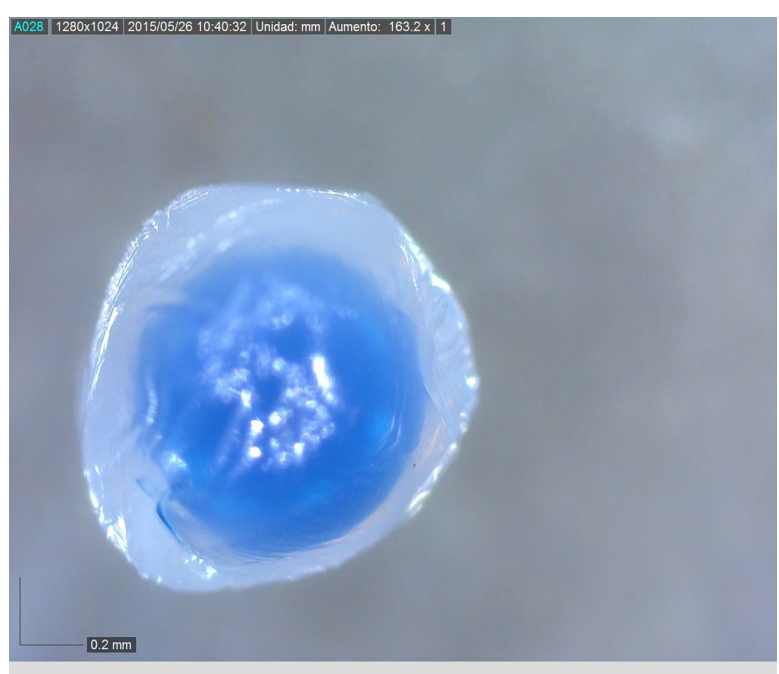

(a)

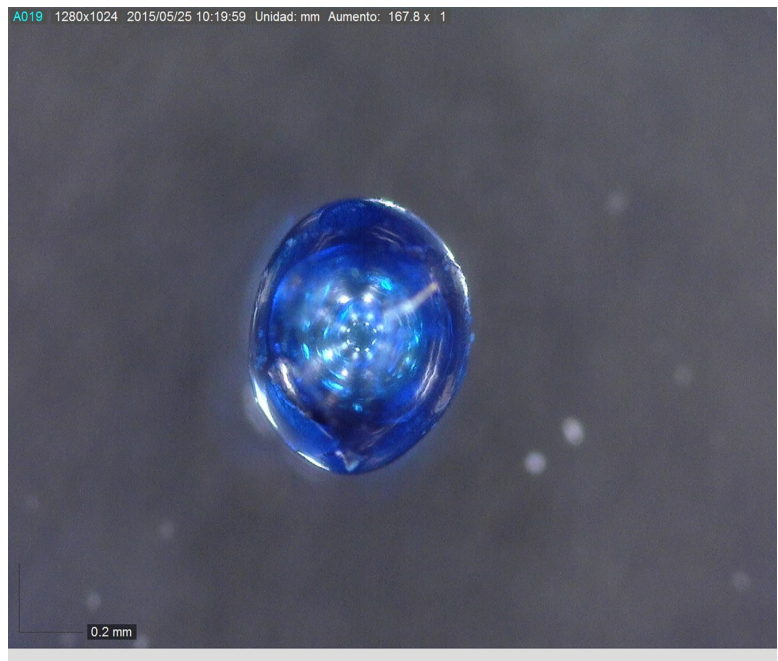

(b)

Figure 3. (a) Non-dry microcapsule (163.2×); (b) Dry microcapsule (167.8×).

Table 2. Morphology values of non-dry and dry microcapsules.

\begin{tabular}{cccc}
\hline \multirow{2}{*}{\begin{tabular}{c} 
Microcapsules \\
\cline { 2 - 3 }
\end{tabular}} & Area $\left(\mathrm{mm}^{2}\right)$ & Morphology parameters \\
\hline Non-dry & 0.709 & 0.950 & 0.273 \\
Dry & 0.449 & 0.756 & - \\
\hline
\end{tabular}


separation distance of the nozzle to the bath, the effect of gravity, the surface tension of the inducing gelation solution, the gel time, alginate viscosity, etc., all of them have influence in the microcapsules sizes [20].

\subsection{Particle Size Distribution}

Figure 4 shows the particle size distribution of non-dry and dry microcapsules, certain differences can be observed, and also that these results meet with the morphology results.

Non-dry microcapsules contain water, so their size is bigger than the one of dry microcapsules. Otherwise, dry microcapsules, having a smaller size, are present in a higher number.

The particle size is smaller than expected (external nozzle diameter was used $0.4 \mathrm{~mm}$ ), this is due to the test used an isotonic solution with ions. It is possible that these ions replace the sodium/calcium ions in the alginate polymer.

Alginate microcapsules were obtained because sodium alginate needs to come into contact with divalent ions such as calcium $\left(\mathrm{Ca}^{2+}\right)$ to form the gel. As soon as sodium alginate is added to a solution of calcium chloride, a gel forms as the sodium ions $\left(\mathrm{Na}^{+}\right)$are exchanged with calcium ions. Depending on the concentration of calciumions, the gels are either thermoreversible (low concentrations) or not (high concentrations). In this case, the gel (shell of microcapsule) is reversible and the ions present in an isotonic solution replace of calcium ions and the gel structure is affected [21].

\subsection{Differential Scanning Calorimetry}

Figure 5 shows a differential scanning calorimetric diagram.

Rosemary oil curve shows that at $130^{\circ} \mathrm{C}$, it decomposes. This is an important value to consider in the drying process.

Alginate, wall material and microcapsules present a step at $80^{\circ} \mathrm{C}$, this corroborates that the drying process used is the correct.

\subsection{Termogravimetry Analysis}

Figure 6 shows three curves corresponding to the rosemary oil, wall material and microcapsules.

Rosemary oil curve shows that at temperatures above $130^{\circ} \mathrm{C}$ it decomposes.

Wall material and alginatecurve presents two steps. The first one, until $100^{\circ} \mathrm{C}$ is caused by the external part moisture and the second one, $100^{\circ} \mathrm{C}-180^{\circ} \mathrm{C}$, is due to the water present within the microcapsules.

\subsection{Control Release}

As a result of the delivery assays, it was observed that oil quantity in non-dry and dry microcapsules is the same. Thus corroborating that, the drying process used is correct and therefore no loss of oil in it (Table 3 and Table 4).

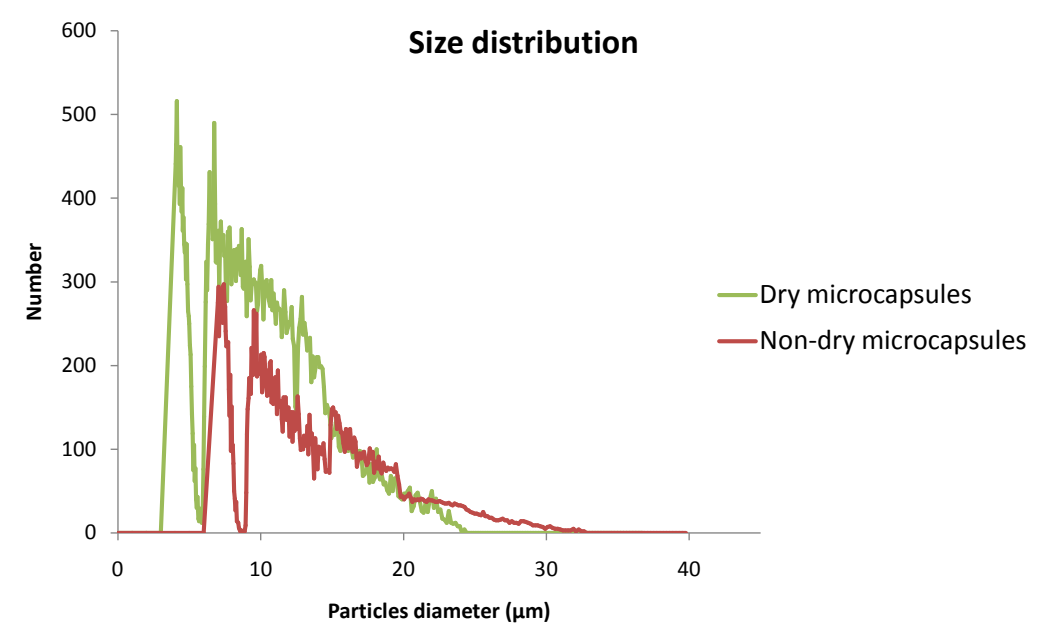

Figure 4. Microcapsules sizes distribution. 


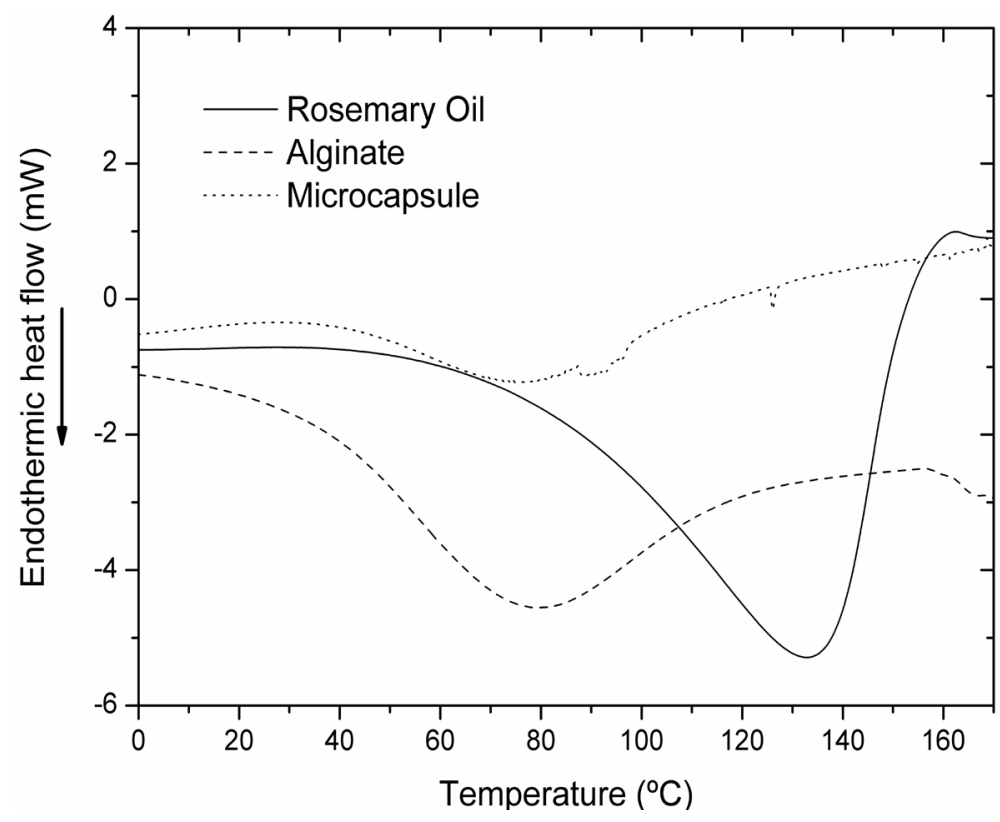

Figure 5. DSC thermograms.

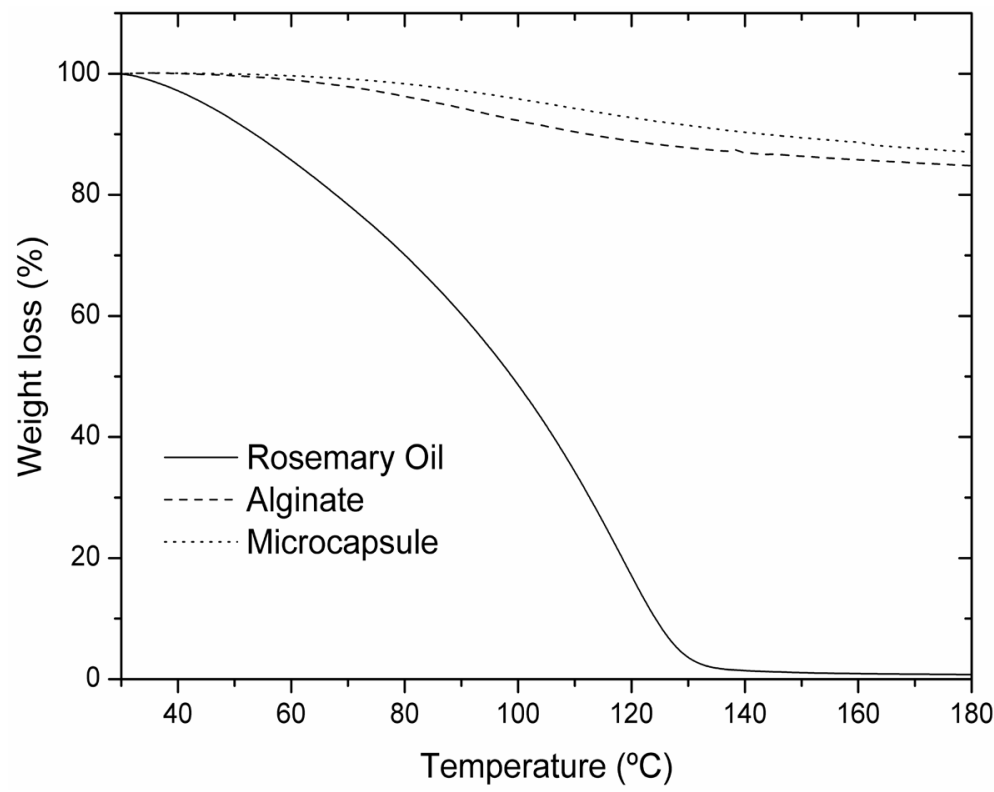

Figure 6. Termogravimetry diagram.

Table 3. Control release of non-dry microcapsules.

\begin{tabular}{ccc}
\hline & \multicolumn{2}{c}{ Delivery of non-dry microcapsules } \\
\cline { 2 - 3 } Experiments & Absorbance & Oil (g) $/ 0.5$ g microcapsules \\
\hline 1 & 2.801 & 0.035 \\
3 & 2.618 & 0.032 \\
Average & 2.791 & 0.034 \\
\hline
\end{tabular}




\subsection{Antimicrobial Test}

Rosemary essential oil was tested as an antimicrobial and antifungal. It presented an excellent reduction at the bacteria and fungi test (Table 5).

\subsection{Chromatography}

Figure 7 shows the contents of the five major components that have been identified in the samples of rosemary essential oil. $\alpha$-pinene, $\beta$-pinene, cineole, camphor and cariophyllene. All of them areterpenes. Scientific literature presents the same major components (cineole, camphor, and $\alpha$-pinene), which are present also in this study [22]. Some terpenes like pinene and camphor have antimicrobial properties [23]. Also, some of the main compounds found (cineole and camphor) in the rosemary essential oil have antifungal properties [24].

\section{Conclusions}

Results show that the co-extrusion/gelling process and subsequent drying allow the microencapsulation of the

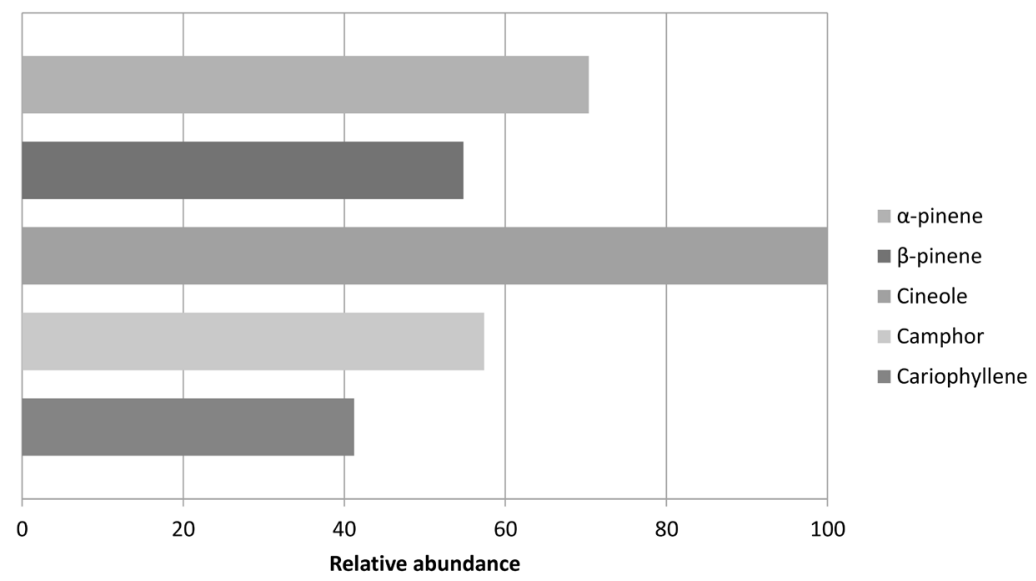

Figure 7. Rosemary oil main compounds.

Table 4. Control release of dry microcapsules.

\begin{tabular}{ccc}
\hline \multirow{2}{*}{ Experiments } & \multicolumn{2}{c}{ Delivery of dry microcapsules } \\
\cline { 2 - 3 } & Absorbance & Oil (g) $/ 0.5$ g microcapsules \\
\hline 1 & 2.845 & 0.035 \\
3 & 2.718 & 0.034 \\
Average & 2.659 & 0.033 \\
\hline
\end{tabular}

Table 5. Antimicrobial test.

\begin{tabular}{cccc}
\hline Microorganisms & Origin & & \% Reduction (cfu/ml) \\
\cline { 3 - 4 } Penicillium citrinum & ATCC 1109 & Rosemary oil & Non-dry microcapsules \\
Rhizopus oryzae & ATCC 11145 & 99.99 & 99.40 \\
Salmonella enterica & ATCC 14028 & 99.99 & 96.30 \\
Escherichia coli & ATCC 25922 & 99.99 & 97.10 \\
\hline
\end{tabular}


rosemary essential oil. It has antifungal and antibacterial properties as shown the antimicrobial test and chromatography, and so it can be an alternative to chemical antimicrobial.

Their controlled and prolonged release, due to the microencapsulation process, increases their useful life.

Optical microscopy is a technique which allows knowing whether or not oil is present inside the microcapsules.

Different technical analytical techniques, DSC, TGA and control release, corroborate that drying process is optimal at $60^{\circ} \mathrm{C}$ and it does not cause loss of oil.

The size and shape of the microcapsules depend largely on the nozzle diameter $(0.4 \mathrm{~mm})$, but there are aspects that can be modified, such as separation distance of the nozzle to the bath, vibration frequency, flow rate, electrode tension, the effect of gravity, the surface tension of the inducing gelation solution, the gel time, and alginate viscosity. The size can be changing when microcapsules are in a water solution, because the calcium alginate (shell polymer) has a high capacity of swelling.

Furthermore, cross linking concentration $\left(\mathrm{CaCl}_{2}\right)$ is important to obtain a gel (shell) stable and non-reversible.

Coulter ${ }^{\circledR}$ Counter is not a good way to determine the size of the alginate microcapsules due to the use of isoton solution.

Use of non-dry and dry microcapsules depends on the end use.

\section{Acknowledgements}

The autors thank IVACE (Institut Valencià de Competitivitat Empresarial, Spain) and FEDER (Fondo Europeo de Desarrollo Regional, Europe) for the financial support.

\section{References}

[1] Jafari, S., Assadpoor, E., He, Y. and Bhandari, B. (2008) Encapsulation Efficiency of Food Flavours and Oils during Spray Dry. Drying Technology, 26, 816-835. http://dx.doi.org/10.1080/07373930802135972

[2] Ayala-Zavala, J.F., Toro-Sanchez, L., Alvarez Parrilla, E. and Gonzalez-Aguilar, G.A. (2008) High Relative Humidity In-Package of Fresh-Cut Fruits and Vegetables: Advantage or Disadvantage Considering Microbiological Problems and Antimicrobial Delivering Systems. Journal of Food Science, 73, 41-47. http://dx.doi.org/10.1111/j.1750-3841.2008.00705.x

[3] Kailasapathy, K. (2002) Microencapsulation of Probiotic Bacteria: Technology and Potential Applications. Current Issues in Molecular Biology, 3, 39-48.

[4] Paster, N. and Bullerman, L.B. (1988) Mould Spoilage and Mycotoxin Formation in Grains as Controlled by Physical Means. International Journal of Food Microbiology, 7, 257-265. http://dx.doi.org/10.1016/0168-1605(88)90044-X

[5] Paster, N., Menasherov, M., Ravid, U. and Juven, B. (1995) Antifungal Activity of Oregano and Thyme Essential Oils Applied as Fumigants against Fungi Attacking Stored Grain. Journal of Food Protection, 58, 81-85.

[6] Yoshizawa, H. (2004) Trends in Microencapsulation Research. Kona, 22, 22-31. http://dx.doi.org/10.14356/kona.2004009

[7] Soliman, E.A., El-Moghazy, A.Y., El-Din, M.S.M. and Massoud, M.A. (2013) Microencapsulation of Essential Oils within Alginate: Formulation and in Vitro Evaluation of Antifungal Activity. Journal of Encapsulation and Adsorption Science, 3, 48-55. http://dx.doi.org/10.4236/jeas.2013.31006

[8] Fu, Y., Zu, Y. and Chen, L. (2007) Antimicrobial Activity of Clove and Rosemary Essential Oils Alone and in Combination. Phytotherapy Research, 21, 989-994. http://dx.doi.org/10.1002/ptr.2179

[9] Barros-Fernandez, R.V., Vilela, S. and Alvarenga, D. (2014) Gum Arabic/Starch/Maltodextrin/Insulin as Wall Materials on the Microencapsulation of Rosemary Essential Oil. Carbohydrate Polymers, 101, 524-532. http://dx.doi.org/10.1016/j.carbpol.2013.09.083

[10] Genena, A.K., Hence, H., Smania, A. and Souza, S.M. (2008) Rosemary (Rosmarinus officinalis)—A Study of the Composition, Antioxidant and Antimicrobial Activities of Extracts Obtained with Supercritical Carbon Dioxide. Cienciay Tecnología de Alimentos, 28,463-469. http://dx.doi.org/10.1590/S0101-20612008000200030

[11] Amsden, B. (1998) Solute Diffusion within Hydrogels. Macromolecules, 31, 8382-8395. http://dx.doi.org/10.1021/ma980765f

[12] Anbinder, P., Deladino, L., Navarro, A. and Amalvy, J. (2011) Yerba Mate Extract Encapsulation with Alginate and Chitosan Systems: Interactions between Active Compound Encapsulation Polymer. Journal of Encapsulation and Adsorption Science, 1, 80-87. http://dx.doi.org/10.4236/jeas.2011.14011

[13] McHugh. D. (1987) Production and Utilization of Products from Commercial Seaweeds. FAO Fisheries Technical 
Paper.

[14] Neira-Carrillo, A. and Yáñez, D. (2013) Encapsulación de Biomoléculas Usando Polímeros Naturales: "Un Nuevo Enfoque en la Entrega de Fármacos en Medicina”. Avances en Ciencias Veterinarias, 28.

[15] González, G.G. (2009) Estabilidad e intercambio de iones calcio en geles de alginato. Instituto tecnológico de Durango, Victoria de Durango.

[16] Serp, D., Mueller, M., Stockar, U. and Marison, I.W. (2002) Low-Temperature Electron Microscopy for the Study of Polysaccharide Ultrastructures in Hydrogels. II. Effect of Temperature on the Structure of $\mathrm{Ca}^{2+}$-Alginate Beads. Biotechnology and Bioengineering, 79, 253-259. http://dx.doi.org/10.1002/bit.10287

[17] Hernández, G. and Tisnado, R. (2012) Avances tecnológicos en la producción de alginatos en México. Ingeniería Investigación y Tecnología, 2, 155-168.

[18] Capablanca, L., Bonet, M., Bou, E., Ferrándiz, M., Franco, E. and Dolçà, C. (2014) Aplicación de técnicas biotecnológicas y de microencapsulación para la funcionalización de agrotextiles. II Congreso de I+D+I Campus Alcoi: Creando Sinergias, Alcoi, 12 Noviembre 2014, 17-20.

[19] Ferrándiz, M., Franco, E., Pascual, M., Dolçà, C., Capablanca, L., Díaz, P. and López, F. (2015) Potencial and Frequency Influence on the Microcapsules Formation by Co-Extrusion and Gelling. Proceedings of the Innovative Solutions for Sustainable Development of Textiles and Leather Industry, Oradea, 22-23 May 2015, 39-42.

[20] Chan, E.S., Lee, B.B., Pogaku, R. and Poncelet, D. (2009) Prediction Models for Shape and Size of Ca-Alginate Macrobeads Produced through Extrusion-Dripping Method. Journal of Colloid and Interface Science, 338, 63-72. http://dx.doi.org/10.1016/j.jcis.2009.05.027

[21] Mørch. Y.A. (2008) Novel Alginate Microcapsules for Cell Therapy-A Study of the Structure-Function Relationships in Native and Structurally Engineered Alginates. Norwegian University of Science and Technology, Trondheim.

[22] Miladi, H. and Ben Slama, R. (2013) Essential Oil of Thymus vulgaris L. and Rosmarinus officinalis L.: Gas Chromatography-Mass Spectrometry Analysis, Cytotoxicity and Antioxidant Properties and Antibacterial Activities against Foodborne Pathogens. Journal of Encapsulation and Adsorption Science, 6, 729-739.

[23] Ecosmart Technologies, Inc.(2012) Antimicrobial Formulation. US Patent No. US 2012/0252893 A1.

[24] Matsuzaki, Y., Tsujisawa, T., Nakamura, M. and Kakinoki, Y. (2013) Antifungal Activity of Chemotype Essential Oils from Rosemary against Candida albicans. Open Journal of Stomatology, 3, 176-182. http://dx.doi.org/10.4236/ojst.2013.32031 